\title{
Editorial
}

\section{Computational Methods in Design and Manufacturing Processes}

\author{
Sutasn Thipprakmas $\mathbb{D}^{1},{ }^{1}$ Yingyot Aue-u-lan, ${ }^{2}$ \\ Anders E. W. Jarfors, ${ }^{3}$ and Suwat Jirathearanat ${ }^{4}$ \\ ${ }^{1}$ King Mongkut's University of Technology Thonburi, Bangkok, Thailand \\ ${ }^{2}$ King Mongkut's University of Technology North Bangkok, Thailand

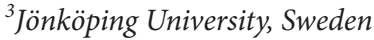 \\ ${ }^{4}$ Singapore Institute of Manufacturing Technology (SIMTech), Singapore \\ Correspondence should be addressed to Sutasn Thipprakmas; sutasn.thi@kmutt.ac.th
}

Received 10 April 2019; Accepted 10 April 2019; Published 9 May 2019

Copyright (C) 2019 Sutasn Thipprakmas et al. This is an open access article distributed under the Creative Commons Attribution License, which permits unrestricted use, distribution, and reproduction in any medium, provided the original work is properly cited.

During the last decades, across all fields of engineering sciences, the evolution of complex systems in design and manufacturing processes has progressed along with the development of computational methods that can treat more and more complex design and simulation problems. Many design and manufacturing processes are now tackled using computational methods that aim at improvement in manufacturing performance. The development of increasingly sophisticated computational methods and the improvement in computer performance represent an emerging issue from both an industry and an academic viewpoint. Nowadays, a lot of research activities in the field of design and manufacturing processes have been accomplished and there are a wide range of applications where the computational methods are used.

The objective of this special issue is to present a wide spectrum of computational methods used as a valuable tool for solving more and more complex design and manufacturing processes as well as providing readers with a representative outlook of the latest achievements in this field. The focus of this special issue is placed on the understanding of the enabling computational simulation to replace a big data of experiments and computational optimization to handle and implement multidisciplinary design in complex manufacturing processes.

This special issue offers an articulated overview of the examined topics. It contains fourteen original research articles. Eight research articles in this special issue cover a wide range of computational simulation techniques to design and construct mechanical elements applied in several manufacturing processes such as a high-energy mill for handling magnesium powder and to design PID controllers. Four research articles discuss various computational optimization techniques to determine optimal working process parameters applied in several manufacturing processes such as a pickand-place optimization of the die attaching process in semiconductor industry and an optimization of a robotic arm under fuzziness. Two research articles in this special issue also address computational evolving techniques for casting process modeling and a new mathematical method applied to the singularity problem of 3-RSR multimode mobile parallel mechanism.

The guest editors hope the information provided in this special issue is useful and offers stimulation to the new developments and applications of computational methods in design and manufacturing processes.

\section{Conflicts of Interest}

The editors declare that they have no conflicts of interest.

\section{Acknowledgments}

We would like to thank the authors for the excellent contribution of their research works. We also would like to thank the reviewers for their time and valuable review results.

\footnotetext{
Sutasn Thipprakmas

Yingyot Aue-u-lan

Anders E. W. Jarfors

Suwat Jirathearanat
} 




Advances in

Operations Research

\section{-n-m}
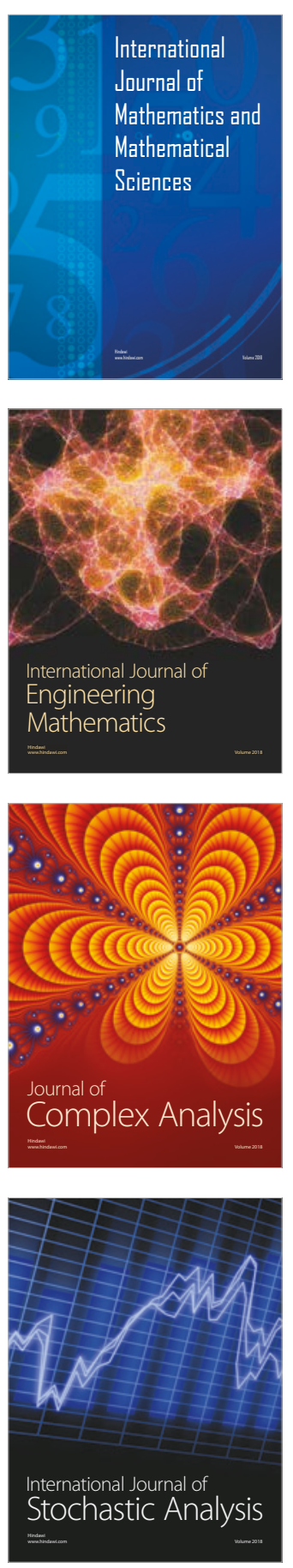
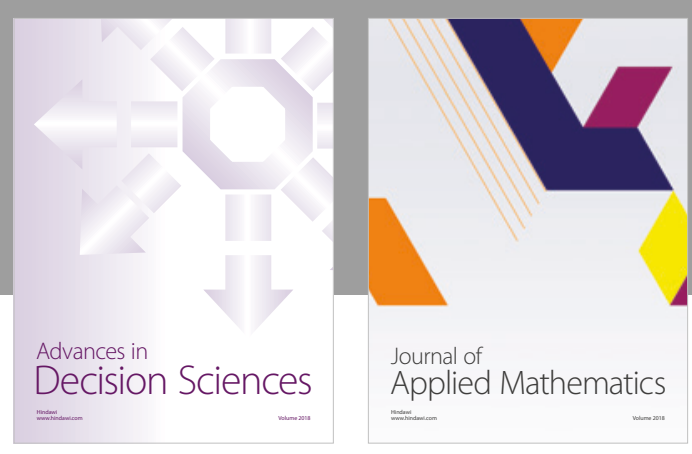

Journal of

Applied Mathematics
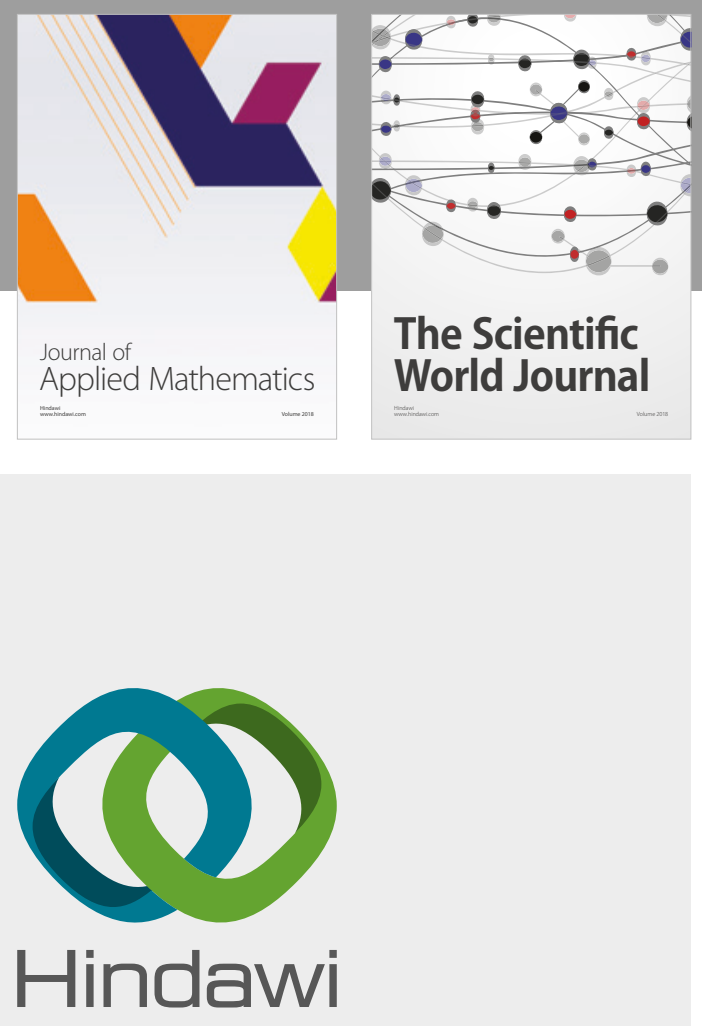

Submit your manuscripts at

www.hindawi.com

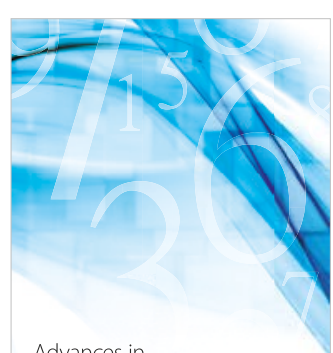

Advances in
Numerical Analysis
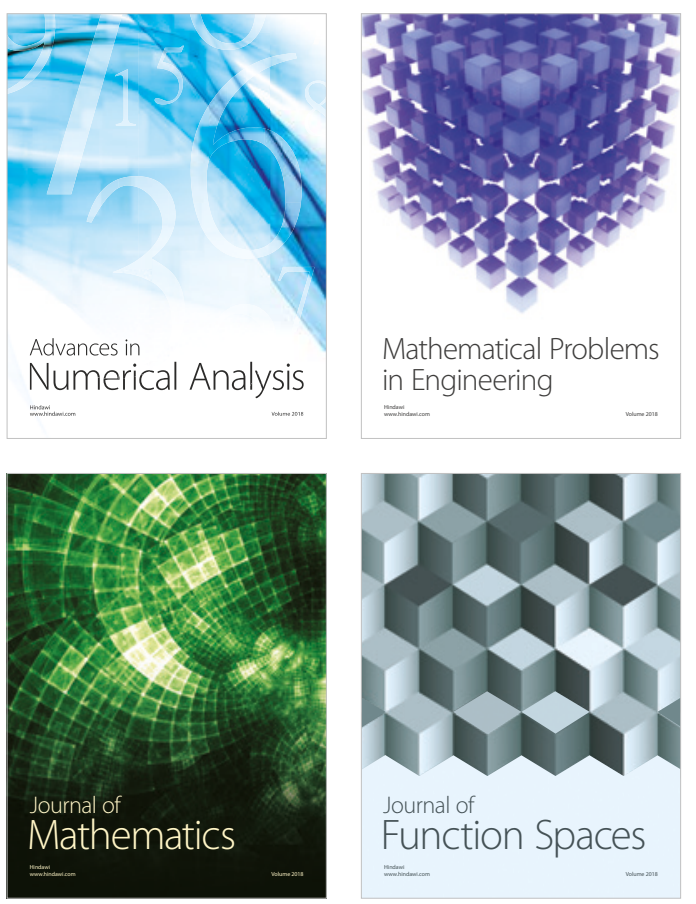

Mathematical Problems in Engineering

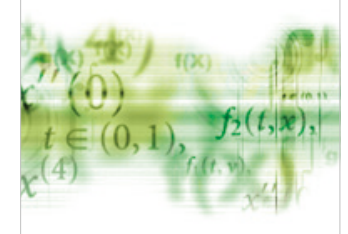

International Journal of

Differential Equations

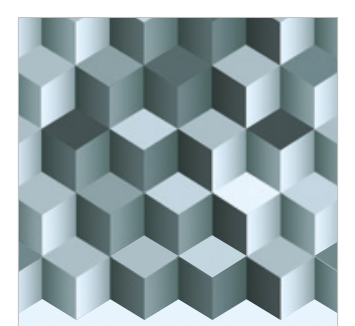

Journal of

Function Spaces

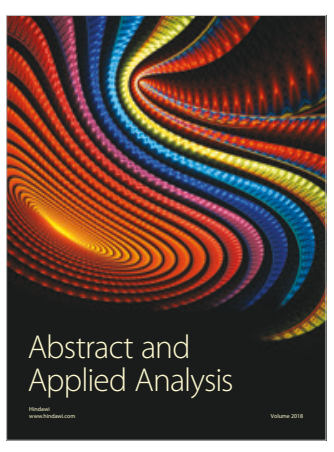

The Scientific

World Journal



Journal of

Probability and Statistics
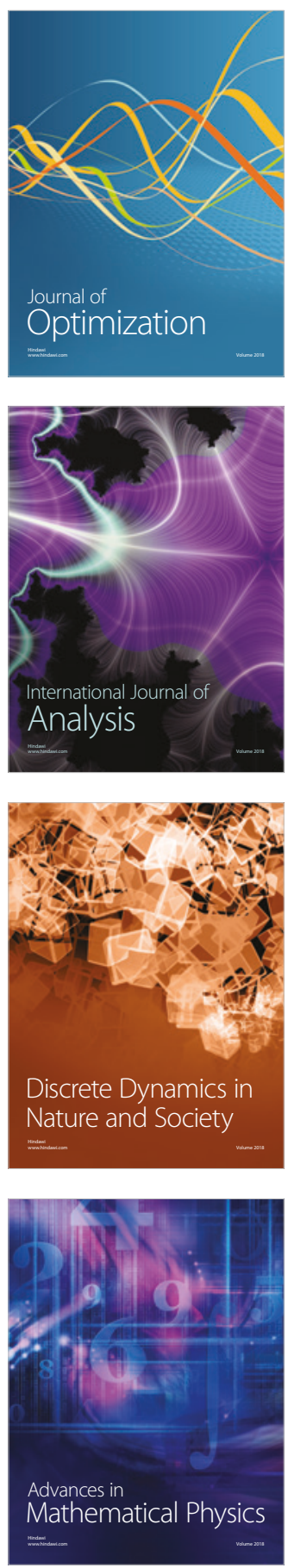